\title{
The rise of national central banks' TARGET balances in the euro area: a comment
}

\author{
Andrea Terzi \\ Franklin University Switzerland, Sorengo, Switzerland
}

With the implementation of the Eurosystem's asset purchase programme (APP), national central banks' TARGET balances have risen. For the European Central Bank, this reflects cross-border payments and portfolio rebalancing in the context of the APP. Minenna et al. (2018) disagree and claim that the causes of rising TARGET balances (2015-2017) have been the persistent currentaccount surplus of Germany and 'capital flight.' This comment explains that rising TARGET balances occur under specific monetary policy configurations and that the context of the APP was critical to account for rising TARGET balances. It then questions the decomposition approach employed by the authors by arguing that it shows accounting correspondences, not causality, and concludes that there is no established two-way association between TARGET balances and actual vulnerabilities of the euro area.

Keywords: TARGET, TARGET2, payment system, quantitative easing, asset purchase program, interbank market

JEL codes: E42, E44, E52, E58

\section{INTRODUCTION}

With the implementation of the Eurosystem's asset purchase programme (APP), TARGET balances of national central banks (NCBs) of the euro area (EA) have risen. ${ }^{1}$ In a recent article in this journal (Minenna et al. 2018), Marcello Minenna, Giovanni Dosi, and Andrea Roventini (MDR) consider three countries in the euro area (Italy, Spain, and Germany) to study 'T2 imbalances and their consequences by performing a decomposition of T2 balances through the analysis of the financial accounts of the balance of payments' (ibid.: 147). The authors challenge the European Central Bank's (ECB) view that the NCBs' rising TARGET balances since the start of the APP 'are only apparently capital flights and depend mainly on the mechanics of QE' (ibid.: 149). MDR claim instead that 'the main determinant of deterioration of the Italian T2 balance ... [is] a reallocation of non-financial private sector wealth from government bonds to foreign bonds, mutual funds, and shares' (ibid.: 152) and that '[ $t$ ]he flows were too strong to simply be downplayed as a physiological strategy of risk diversification' (ibid.: 152). They also maintain that the 'availability of fresh central-bank money and a weaker euro have encouraged

1. TARGET is the name of the decentralized Trans-European Automated Real-time Gross Settlement Express Transfer System that in May 2008 was fully replaced by the single platform, named TARGET2 (or T2). Following the ECB, the balances accumulated by central banks in both generations are here referred to simply as TARGET balances.

Received 20 December 2018, accepted 23 January 2019 
banks, firms, and investors to engage in a multitude of cross-border transactions that have inflated T2 accounts of many, but not all, eurozone central banks' (ibid.: 158) and allude 'to the perception of a "capital flight"' (ibid.: 149). On the other hand, 'the main cause [of the German T2 balance] can be attributed to the uninterrupted growth of the cumulative surplus of the current-account' (ibid.: 154). MDR conclude that 'the increasing imbalances in the T2 system show ... that ... the European Monetary Union (EMU) does not have any built-in stabilizing mechanisms to foster the convergence of European economies. In such a framework, institutional reforms in the EMU ... are urgently needed to avoid catastrophic consequences' (ibid.: 158).

This comment does not take issue with the authors' general statement in support of institutional reform. That Europe's Economic and Monetary Union is incomplete is a widely accepted claim, and MDR do not address the more important, and controversial, question of the choice and the priority of reforms. Likewise, it is common knowledge that portfolio rebalancing has taken place in the euro area (including Italy, Spain, and Germany) since $2015^{2}$ and that Germany runs a significantly large current-account surplus. This comment takes issue, rather, with the decomposition approach employed by the authors and with the implications that they draw from it. In what follows, I begin with an account of how TARGET balances depend on alternative monetary policy configurations, and I subsequently offer reasons why MDR's argument is not convincing.

\section{TARGET BALANCES UNDER DIFFERENT MONETARY POLICY CONFIGURATIONS}

While the determinants of central banks' TARGET balances at any given time are complex and variable, the accounting logic is straightforward. TARGET2 is the European platform for cross-country, single-currency, interbank payments in central-bank money (CBM). Because CBM is a liability of central banks, a transfer of funds between banks in the same jurisdiction is settled via an 'in-house' payment, whereby the central bank correspondingly credits, and debits, the overnight accounts of the receiving and of the sending bank. Likewise, when the central bank sends a payment to a bank (or receives a payment from a bank) located in its own jurisdiction, it will credit (or debit) the overnight account of the bank by creating (or extinguishing) a central-bank liability (that is, CBM) to the receiving (or sending) bank.

Under the single currency in Europe, each NCB (for example, the Bank of Italy) has, in addition, the ability to settle a payment (for its own account or on behalf of a bank in its jurisdiction) to a bank located outside its own jurisdiction (for example, in Germany). Ignoring some minor technical details, ${ }^{3}$ this requires two steps: the NCB sending the payment will credit the Eurosystem (and not the bank in Germany directly) by creating an NCB's intra-Eurosystem (TARGET) liability; and on receiving an intra-Eurosystem (TARGET) claim, the other NCB (for example, the Deutsche Bundesbank) will credit the receiving bank by creating an NCB's liability (CBM) to that bank.

As with any secure and reliable CBM-based payment system, the TARGET2 platform provides payment and settlement services for its participants without imposing an upper boundary on the amounts that can be processed during the day. Typically, however, central banks (and the Eurosystem is no exception) set restrictions on banks' permitted overnight

2. Bua/Dunne (2017) offer an extensive analysis of the transmission of the ECB's asset purchase program via the redirection of funds, largely toward non-euro assets.

3. For a more detailed account of the underlying mechanics of the TARGET2 system, see Bindseil/ König (2011). 
account balances at the end of the business day, and this creates a market for overnight balances. To avoid penalties, a sending bank that is short of CBM can receive funds in the interbank market from a receiving bank with excess CBM. If funds between banks shift smoothly, the banking system as a whole operates with an overall amount of end-of-day overnight balances equal (or very close) to the required minimum.

Over any given period, if the value of net payments made (or received) by the residents of one EA country to (or from) another jurisdiction (for either economic or financial transactions) is fully (or almost fully) offset by an equivalent amount of funds via the interbank market, the NCB's intra-Eurosystem (TARGET) balances are zero (or near zero). Accounting-wise, changes in the net external assets of the banking system of each EA jurisdiction (vis-à-vis the rest of the euro area, RoEA) will mirror all other economic and financial flows in the balance of payments (vis-à-vis the RoEA). This was the ordinary scenario before 2007 in the EA: a zero (or close to zero) TARGET balance position for each NCB was consistent with any balance-of-payments position with the RoEA.

There are two hypothetical variations of this case: a demand-driven scenario and a supplydriven scenario. The demand-driven scenario applies to conditions of financial stress. When the interbank market stops functioning - that is, when receiving banks are no longer willing to offer CBM to the sending banks at a price below the policy rate - then the latter will find it convenient to access the liquidity facility of their NCB. The Eurosystem thus deploys its balance sheet 'passively' to provide banks with overnight balances (CBM) over and above the required minimum: the sending bank borrows from its $\mathrm{NCB}$, settles the payment due, and the receiving bank accumulates excess CBM.

In the demand-driven scenario, NCBs' TARGET balances remain unaffected only if the banks losing access happen to be evenly distributed across the countries of the currency union. ${ }^{4}$ Instead, if the banks losing access to the interbank market are concentrated in a few jurisdictions, NCBs' TARGET claim and liability balances are bound to rise. ${ }^{5}$ Specifically, the NCB of the jurisdiction that hosts the banks that sell their claims on cross-border (intra-EA) entities (on their own or their clients' account), stop lending cross-border (intra$\mathrm{EA})$, and accumulate overnight balances (CBM), will send no offsetting interbank payments and its TARGET claims will rise. Correspondingly, the NCB of the jurisdiction that hosts the banks that have lost access to the interbank market will not receive offsetting interbank payments, and its TARGET liabilities will rise. This demand-driven scenario applies to the years of financial stress in Europe (2008-2012), when loss of market access was countryspecific, with a dramatic repricing of risk premiums and rising bank credit risk, and hence TARGET balances considerably diverged from zero.

The second (supply-driven) scenario applies when the Eurosystem deploys its balance sheet 'actively' by implementing an asset purchase program (often termed 'quantitative easing') in an effort to affect broad financial conditions. Asset purchases create additional banks' overnight account balances (CBM) that exceed the required minimum. This supply-driven scenario applies to the APP that the Eurosystem (that is, all EA NCBs and the ECB) put into force in 2015 through the purchase of private and public securities (on predetermined proportions) with no 'sterilization' that reabsorbs the excess balances through open-market operations.

4. Under the demand-driven scenario, the ECB will still show a TARGET liability if it directly provides funding to banks, or a TARGET claim if it swaps foreign currency for CBM (such as with the bilateral currency swap agreement with the US Federal Reserve in 2008-2009).

5. Hence, a necessary (but not sufficient) condition for the rise of TARGET balances is that the overall amount of end-of-day overnight balances exceeds the required minimum set by the ECB. 
In the supply-driven scenario, the TARGET balances (that is, claims and liabilities) of all NCBs are bound to rise depending on the jurisdictions that host the accounts of the sellers of the securities. When purchasing securities, central banks do not choose the sellers of securities, as they seek offers from security dealers and buy from the one offering the security at the lowest ask price. NCBs' TARGET balances remain unaffected only if it happens that security sellers to each NCB are uniquely domestic banks (or their depositors) or that cross-border security purchases perfectly offset each other. ${ }^{6}$ If, instead, the sellers of securities happen to be banks (or their depositors) concentrated in a few jurisdictions, then TARGET claim and liability balances will rise. The TARGET balances of the NCBs of the jurisdictions where the banks providing settlement services to the sellers of securities ${ }^{7}$ are concentrated will record an increase in TARGET claims, while the other NCBs will record an increase in TARGET liabilities.

Eisenschmidt et al. (2017) provide evidence that supports the hypothesis that this has been the case for the EA in the years of the APP. In Europe, a few financial centres (notably Germany, the Netherlands, Luxembourg, and Finland) act as important gateways between the EA and the rest of the world (RoW), ${ }^{8}$ and non-EA sellers of securities are likely to request payment to their bank deposits in one of these jurisdictions. Consistently, the TARGET balances of the NCBs of these countries record an increase in claims, while other NCBs (including the ECB) record an increase in liabilities. ${ }^{9}$ In addition, the ample liquidity conditions prompted a fall in market yields (which was one of the goals of the APP), and this widened the interest-rate differentials between non-EA and EA debt securities, ${ }^{10}$ triggering a portfolio rebalancing in the form of net purchases of non-EA securities by EA residents and a reduction of non-residents' holdings of EA securities. ${ }^{11}$ Accordingly, and as long as the settlement location of financial transactions between the EA and the RoW happens to be in a few international finance gateways in Europe, the subsequent portfolio rebalancing makes the NCBs' TARGET balances rise further. Hence, for example, Italian banks that settle payments on behalf of their clients purchasing non-EA securities might need to settle payments with German banks.

One could still wonder why, if it is true that the interbank market is no longer under the financial stress of 2008-2012, the CBM that flows to the financial centres does not eventually flow back to the banks in those jurisdictions (such as Italy or Spain) where the

6. Under the supply-driven scenario, the ECB's TARGET balance will still show a liability if the ECB makes security purchases on its own account (that is, outgoing payments), given that the ECB does not offer overnight accounts to banks and thus does not receive incoming payments.

7. The sellers of securities may or may not be EA residents.

8. Banks in Germany and the Netherlands traditionally serve as correspondent banks to non-EA banks. Luxembourg is a main domicile for the investment fund industry. Finland has close ties to Nordic banks. The NCBs of these four countries have posted the four largest absolute increases in TARGET claims in the APP period (March 2015 through December 2018).

9. The ECB's TARGET liabilities with the Eurosystem rise with the amount of securities purchased directly by the ECB, while the corresponding claims appear on the balance sheets of other $\mathrm{NCBs}$, depending on what country hosts the security seller's account. The relevant NCB, in its turn, will credit the bank selling the security (on its own account or on that of its clients), thus increasing its liabilities to EA credit institutions.

10. In 2015-2017, money market yields in Germany, Italy, and Spain have been on a downward trend and permanently below zero in the second half of this three-year period, while money market yields in the US have been on a rising trend, from a low of 0.18 percent in January 2015 to a high of 1.76 percent in December 2017 (source: Macrobond Financial).

11. Portfolio rebalancing was one consequence of the APP that contributed to the weakening of the euro in the foreign-exchange market. 
NCB's TARGET account shows a liability position. The answer is that Italian and Spanish banks' overnight balances are well over the required minimum. At the end of November 2018, Italian banks' current account plus deposit facility at the Bank of Italy amounted to $€ 88.5$ billion, while the average required minimum in the maintenance period amounted to $€ 15.3$ billion. ${ }^{12}$ With such ample liquidity conditions created by the APP, the interbank market daily volume has constantly dropped since $2015 .{ }^{13}$ In addition, the small spread between the rate on the deposit facility and the interest rate on fixed-rate full-allotment operations, as well as the increased regulatory costs of interbank lending, have further reduced both lenders' and borrowers' incentives to access the interbank market.

This drying-up of interbank lending and borrowing has two main consequences. First, any credit risk in interbank lending may not be visible. Second, over any given period, the value of net payments made (or received) by the residents of one EA jurisdiction to (or from) another jurisdiction (that is, intra-EA economic or financial transactions), if it is no longer offset by an equivalent amount of funds via the interbank market, will affect TARGET balances rather than banks' external positions, with an important caveat: The role of a few jurisdictions as financial centres may disconnect TARGET balances from current-account balances, even when receiving banks no longer lend to sending banks. ${ }^{14}$

\section{THE 'DECOMPOSITION' OF TARGET BALANCES SHOWS ACCOUNT- ING CORRESPONDENCES, NOT CAUSALITY}

In their paper, MDR analyse the balance of payments of Italy, Spain, and Germany to develop a 'decomposition' of the TARGET balances of the Bank of Italy, the Banco de España, and the Bundesbank. They express reservations about the explanatory power of cross-border operations and point to the rising net purchases of foreign assets (in all three countries) as the cause of rising balances, with the exception of Germany, where the current-account surplus has more than offset such purchases. The authors view the rising TARGET balances as worrying signs of divergence in two respects: 'capital flight' out of peripheral economies and 'the uninterrupted growth of the cumulative surplus of the [German] current-account' that they claim to be 'the main cause' of the rising TARGET claims of the Bundesbank (Minenna et al.: 154).

There are several reasons why MDR's argument is not convincing. While expressing general skepticism towards the ECB's view, MDR do not disprove the hypothesis that two main conditions account for the rising TARGET balances since 2015: (a) the size of NCBs' cross-country (APP) purchases and the concentration in a few jurisdictions of specialized correspondent banks that settle payments with non-resident entities; and (b) the subsequent portfolio rebalancing.

12. Sources: ECB Statistical Data Warehouse and Bank of Italy BDS. Spanish banks are in a similar position.

13. Daily volume for the overnight maturity dropped to $€ 2$ billion in December 2018, compared to $€ 30$ billion in January 2015 (source: ECB Statistical Data Warehouse).

14. As an example, suppose that (with an interbank market virtually dead) Italian imports from the US are settled through German banks and that Italian exports are settled directly with US banks. Then, an Italian surplus with the non-EA world would be consistent with an increase in the Bank of Italy's TARGET liabilities, while an increase in the Bundesbank's TARGET claims would be unrelated to the German current account. 
Regarding (a), MDR speculate that the share of cross-border purchases by the NCBs of Italy and Spain are likely to be well below the assumption of the ECB. They claim that $\mathrm{NCBs}$ are likely to 'make purchases from domestic and foreign investors using a uniform trading pattern,' reflecting the holding shares between residents and non-residents, and thus 'one should expect that they will grossly respect this subdivision' (ibid.: 149). Here, the authors seem to disregard the fact that NCBs do not use any trading pattern other than taking the lowest dealers' ask price, and the probability that counterparties are non-resident entities does not necessarily mirror their holding shares, especially if foreign investors have sold disproportionally to domestic investors. In addition, the location of the counterparty is not necessarily equivalent to the location of the seller.

On this point, it must be noted that MDR seriously misinterpret the meaning of the growth of the deposits in euros of non-euro residents at the Bundesbank (as displayed in their figure 6). For the authors, this 'is evidently linked to the purchase of government bonds by the Bundesbank' that they connect 'to the Bundesbank role of hub when purchasing securities on behalf of banks outside the euro area' (ibid.: 154, emphasis in original). This is not the case. As discussed above, when the Bundesbank settles other NCBs' security purchases from non-EA residents, it receives TARGET claims and increases its liabilities by crediting the overnight balances of the German bank that is selling the securities on behalf of the non-EA resident. Contrary to what the authors claim, the growth of euro deposits of non-euro residents at the Bundesbank (an item called Liabilities to noneuro area residents - denominated in euros) is not influenced by APP purchases of either the Bundesbank or other NCBs. The increase in that series is mainly related to deposits of non-EA central banks and monetary authorities at the Bundesbank. ${ }^{15}$

Regarding (b), MDR claim that the Italian private sector's purchases of foreign assets 'were allowed by the monetary policy of the Bank of Italy, which purchased government bonds from private investors, thus providing the necessary financial resources' (ibid.: 152). ${ }^{16}$ This statement, however, is questionable. Private investors willing to sell the bonds they were holding and purchase foreign assets could definitely do this before the APP. If they increasingly did so with the APP, it is because the Eurosystem's asset purchases had an impact on the price structure of financial assets, not because there was a shortage of funds needed for payment before the APP.

Still regarding (b), MDR seem to concur with the ECB's view (ECB 2017) that international portfolio rebalancing contributed to the further rise of TARGET balances. Because a few financial centres have acted as important gateways between the EA and the RoW, a significant share of the purchases of, say, US Treasuries by private investors located in various jurisdictions of the EA, as well as a significant share of the sales of EA assets by, say, US private investors, have been settled through the banks located in those centres.

Yet MDR view such flows as 'giving rise to the perception of a "capital flight"' (Minenna et al. 2018: 149). On the one hand, MDR rightly acknowledge that the net purchases of non-EA securities by EA residents and the reduction of non-residents' holdings of EA securities have regarded most countries in the EA, including Germany. This seems consistent with the hypothesis that they were a market response to the APP, which triggered the widening of interest-rate differentials with US-dollar-denominated assets and the fall in the foreign value of the euro. On the other hand, MDR claim 'the flows were too strong to simply be downplayed as a physiological strategy of risk diversification' (ibid.: 152). If this means that

15. Source: Deutsche Bundesbank.

16. Because there is no such thing, by 'monetary policy of the Bank of Italy' MDR must have meant the Bank of Italy's implementation of ECB monetary policy. 
they believe that such flows, in 2015-2017, signaled an intra-EA, pathological, financial stress, they should provide more evidence. ${ }^{17}$

The authors' statement that TARGET balances 'must be analysed as the result of movements in the accounts of the balance of payments' (ibid.: 149) is also questionable. From a strictly accounting standpoint, the TARGET balance of an EA country must indeed match the sum of all other items of that country's balance of payments with the RoW (including errors and omissions). From a conceptual standpoint, and as discussed in the previous section, rising TARGET balances depend on monetary policy configurations and their impact on the interbank market. When bank liquidity equals the minimum required and the interbank market works smoothly, TARGET balances are close to zero for any composition of balance-of-payments flows, and banks' external positions (not TARGET balances) will match the sum of all other items of that country's balance of payments with the RoW (including errors and omissions). Hence, 'decomposition' highlights cross-country flows that under a different monetary policy configuration would not trigger a rise of TARGET balances.

In conclusion, MDR fail to persuade that their decomposition of TARGET balances helps to 'shed light on ... financial flows' (ibid.: 149). The flows that the authors highlight (that is, private Italian, Spanish, and German residents' net purchases of foreign securities and a reduction of non-residents' holdings of government bonds issued by these three countries, as well as the hefty German current-account surplus) can be observed quite independently of TARGET balances. ${ }^{18}$ As discussed in Section 2, economic and financial flows may occur with no accumulation of TARGET balances, as was the case in the first ten years of the euro, and TARGET balances rise only under specific monetary policy configurations, not as a result of such flows. A decomposition of TARGET balances that does not fully consider the consequences of alternative monetary policy configurations adds no information that cannot be obtained by direct observation of the balance-of-payments flows. TARGET decomposition reveals accounting correspondences, not causality.

\section{CONCLUSION}

TARGET2 (the second generation of TARGET) is the name of the payment system that makes the single currency in Europe possible. It settles payment transactions in centralbank money with immediate finality. It allows the holder of a bank deposit in any country of the currency union to move it anywhere within the TARGET2 platform, denoting a fundamental difference from the way cross-currency international payments are settled.

Rising NCBs' TARGET balances occur under specific monetary policy configurations, when there is a lack of incentives or opportunities for banks with excess liquidity to access the interbank market. This means that there is no established two-way association between TARGET balances and actual vulnerabilities of the EA. Depending on context, rising TARGET balances may or may not be an indicator of stress, fragmentation, or

17. Unfortunately, MDR have chosen not to review the analysis by Eisenschmidt et al. (2017). This analysis shows that 'there is no time-invariant causal link between changes in TARGET balances and specific components of the BoP' and that 'the analysis of BoP developments during the PSPP period shows that large changes in TARGET balances per se are not an appropriate individual indicator to detect crisis-related external flows' (ibid.: 37).

18. Regarding the German balance of payments, it should be noted that the current-account surplus with the RoEA is now approximately only 30 percent of the current-account surplus with the RoW (source: Eurostat). 
institutional weakness. On the other hand, institutional weakness in the EA was present well before TARGET balances started to rise. ${ }^{19}$

Observations from a decomposition of TARGET balances do not support or disprove MDR's hypothesis that what the ECB has called 'portfolio rebalancing' was really 'capital flight,' nor do they strengthen the case for a reduction of the German current-account surplus. With regard to the latter, one should note that the EA as a whole (not only Germany) now runs a current-account surplus. This entails a drain of real resources from Germany and from the whole EA, increasing financial risks connected with holding assets abroad and dependency on foreign creation of private and public debt that sustains demand for goods and services produced in the EA. This makes a case for creating a common fiscal tool that supports domestic demand in the EA.

TARGET is the pillar that makes central-bank money issued by different central banks fully fungible. By contrast, the pillar that makes bank money (that is, commercial-bank deposits) fully fungible across the EA - that is, a European Insured Deposit Scheme - is still missing, perpetuating considerable vulnerability of the EA.

\section{REFERENCES}

Bibow, J., Terzi, A. (2007): Euroland and the World Economy: Global Player or Global Drag?, Basingstoke, UK: Palgrave Macmillan.

Bindseil, U., König, P.J. (2011): The economics of TARGET2 balances, SFB 649 Discussion Papers, Humboldt University, Collaborative Research Center.

Bua, G., Dunne, P.G. (2017): The portfolio rebalancing effects of the ECB's asset purchase programme, Central Bank of Ireland Research Technical Paper No 07/RT/17.

ECB (European Central Bank) (2017): The ECB's asset purchase programme and TARGET balances: monetary policy implementation and beyond, in: ECB Economic Bulletin, 3, 21-26.

Eisenschmidt, J., Kedan, D., Schmitz, M., Adalid, R., Papsdorf, P. (2017): The Eurosystem's asset purchase programme and TARGET balances, ECB Occasional Paper Series, No 196, September.

Minenna, M., Dosi, G., Roventini, A. (2018): ECB monetary expansions and euro area TARGET2 imbalances: a balance-of-payment-based decomposition, in: European Journal of Economics and Economic Policies: Intervention, 15(2), 147-159.

19. Among others, Bibow/Terzi (2007) investigated the vulnerability of the EA at a time when NCBs' TARGET balances were close to zero. 